\title{
Space Management in "Traditional” Markets of the Yaounde Municipality
}

\author{
Emmanuel E. E. Oben ${ }^{1} \&$ Lawrence F. Fombe ${ }^{1}$ \\ ${ }^{1}$ Department of Geography, FSMS, University of Buea, Buea, Cameroon \\ Correspondence: Lawrence F. Fombe, Department of Geography, FSMS, University of Buea, Buea, Cameroon. \\ Tel: 237-9603-1463. E-mail: ezumeh@hotmail.com
}

Received: October 1, 2013 Accepted: October 24, 2013 Online Published: January 16, 2014

doi:10.5539/jgg.v6n1p28

URL: http://dx.doi.org/10.5539/jgg.v6n1p28

\begin{abstract}
Market Segmentation has become a very fashionable tool in retail organization in markets of Yaounde, the capital of Cameroon. Studies reveal that internal segmentation is not homogeneous in all major markets of the city and this has led to different results in terms of organisation and market security. This study examines the socioeconomic and urban planning implications of unorganised markets, the changes and challenges that organised markets have brought about as part of the overall city planning process. Through stratified random and purposeful sampling techniques, it was found out that incompatibility exist in both types of markets and that the absence of a priori retail planning in markets is the main cause of the anarchy that characterize their growth and development in the Yaounde metropolis. The study further reveals that while in some markets it is the traders who ensure the internal structure in the absence of official intervention, those that are internally planned before their effective occupation reveal not very outstanding results in satisfying the needs of both the traders and customers due to lapses in planning, administration and case specific circumstances of each market.
\end{abstract}

Keywords: markets, segmentation, Yaounde, shopping fatigue, customers, traders, space/time

\section{Introduction}

According to Tracy-White (1995), Thomas (2007), traders are supposed to be organised according to the activities they carry out, their commonality and similarity. The importance of market segmentation has the ability to ease organisation and shopping, improve the quality and quantity of goods sold and services provided as a result of competition within each segment. In a well segmented market atmosphere, decision-makers will be able to define objectives and allocate resources more accurately. Moreover, it can also enhance the predictability of retail space requirements (Blythe, 2005) and ensure maximisation of time and space. Thus, market improvement programs can generate positive socioeconomic benefits by virtue of the fact that it would improve the efficiency of market operations, health protection and improvements on the amenities and aesthetics of markets (Tracy-white, 1995). Recognizing the importance of segmentation in the designing of the Oraifite market in Anambra state, Nigeria, Francis (2012) elaborated on a variety of spaces to cater for different categories of traders and activities. He further explained the importance of in-built flexibility in internal space division to accommodate changes in marketing activities.

The structural organization of goods and services in markets of the Yaounde metropolis has been one of the key concerns of the Yaounde City Council in the past three decades. The first attempt to segment markets was partially done in the Central market in the 1980s with more effective implementation in the Mvog Betsi market in 2004, followed by the Mokolo market in 2012. Segmentation in the Mvog Betsi market was undertaken before effective occupation, while that of the Mokolo market was achieved 48 years after effective occupation. The idea of segmentation is also being implemented in the Etetak market which is still under construction. In other markets like Mvog Mbi, Nsam, EligEdzoa, Essos, Ekounou, Mvog Ada, Acacia, Etoudi, Mfoundi, Nkomo and Mendong, not officially segmented, traders have ensured segmentation due to the absence of an official plan. However, a few markets like Mfoundi and Mvog Ada specialise in the sale of perishables and livestock respectively.

The absence of segmentation from the original occupation of major markets in Yaounde has resulted in the anarchy that characterise their growth and development. Though markets like Mokolo have witnessed segmentation in the course of their development, they exhibit a lot of inefficiency as a result of structural, 
institutional, and socioeconomic factors. In markets that lack an official segmentation order, traders with identical merchandise have grouped themselves in terms of similar goods sold. However, the multiplicity of traders retailing relatively similar commodities within the same market as well as its punctuation by incompatible activities within the same segments has resulted in the chaotic disposition of economic activities and consequently general disorder in the market landscape. Furthermore, problems such as the occupation of sidewalks and streets by traders, and traffic congestion are all signposts of disorder in a characteristically unorganised market system. This renders shopping, administration, and overall planning tedious and militates against the effective utilization of space so as to yield maximum benefits (Fellmann et al., 2005).

Given the historical importance of commerce to towns and cities, this study seeks to examine the socioeconomic and institutional implications of markets not organised a priori, the changes that organised markets have brought about as well as the challenges of segmentation. This is in view to achieve a sustainable market management approach within the context of the Yaounde overall city planning process.

\section{The Study Area}

Yaounde, the capital of Cameroon is located between latitudes $3^{\circ} 47 \mathrm{~N}$ and $3^{\circ} 56^{\prime} \mathrm{N}$ of the Equator and between longitudes $11^{\circ} 10^{\prime \prime} \mathrm{E}$ and $11^{\circ} 45^{\prime \prime} \mathrm{E}$ of the Greenwich Meridian. Figure 1 shows the study area in the Centre Region in Cameroon.

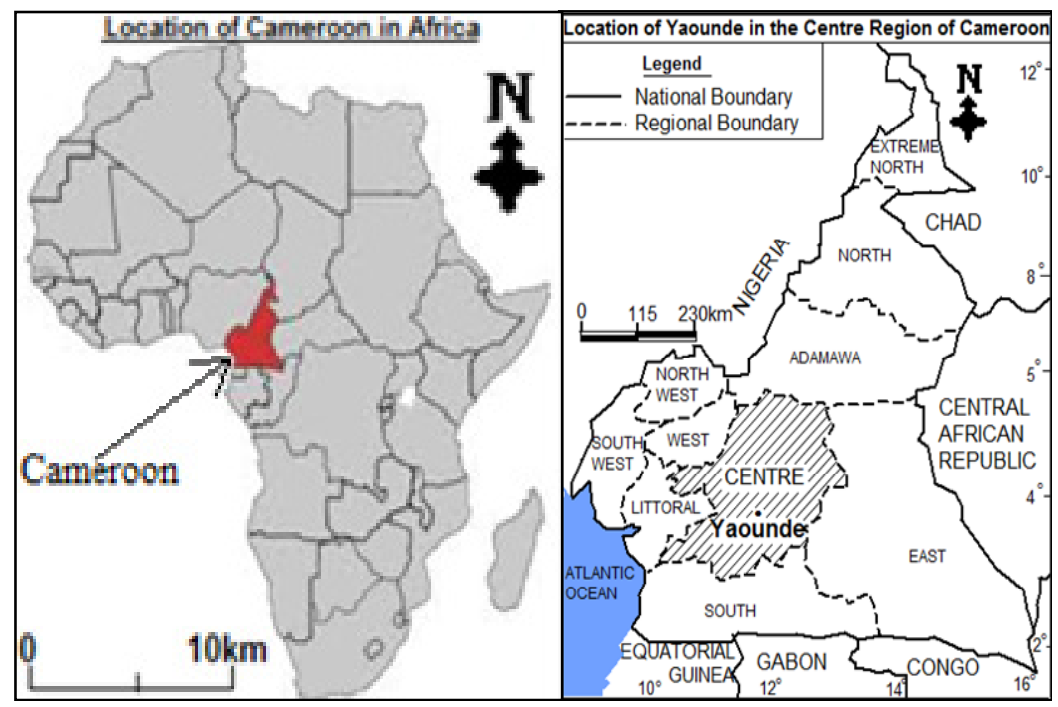

Figure 1. Location of the Yaounde Metropolis in the Centre Region of Cameroon

Yaounde currently has a population of about 2 million inhabitants and has been projected to attain 2.8 million in 2020 (PDU, 2008). According to the Census data of 1976 and 1987 (Fombe \& Balgah, 2010) the migrant population constituted $60.25 \%$ of the population, while the non-migrant population constituted just $39.75 \%$. The surface area of Yaounde increased from $240.98 \mathrm{~km}^{2}$ in 1980 to $287.98 \mathrm{~km}^{2}$ in 2001 . The population density vis-à-vis the surface area is 45.25 people per hectare $(\mathrm{P} / \mathrm{ha})$, while the population density vis-à-vis the urbanised area is 153 P/ha (PDU, 2008). According to the Enquête sur l'Emploi et le Secteur Informelle (EESI) (2005) in the Plan Directeur d'Urbanisme de Yaounde (PDU) (2008), commerce is the second largest employer in the city $(20.90 \%)$ after the service industry which employs $57.80 \%$ of the population. Industries and the primary sector employ $18.80 \%$ and $2.20 \%$ respectively.

\section{Research Design and Methods}

The ex post facto correlated case study design has been used to examine market segmentation over space and time, investigate the problems linked to the inefficiency of segmentation in organised markets, determine the issue of markets being unorganised as well as the difference between organised and unorganised markets in Yaounde. This was achieved through data collection, the use of questionnaires, interviews, observations and analysis of data.

This study is based on an analysis of $72.2 \%$ of markets in Yaounde. One market each was chosen from the seven Sub-Divisions, except for Yaounde VII that does not have an official market, being a recently created 
Sub-Division. Figure 3 shows the sampled markets in each Sub-Division in Yaounde. A total of 180 questionnaires were administered in these markets. Fifteen were administered in each market through a stratified random sampling method and targeting major traders involved in the sales of perishables, clothes and textiles, cosmetics, kitchen utensils, livestock and tailoring to get their views about segmentation. Furthermore, twenty-nine stakeholders (market directors, sub-divisional authorities, market presidents and the commissioner of the Mokolo market) were equally interviewed. These stakeholders were interviewed on the challenges of segmentation in Yaounde markets. The purposeful sampling method was used to identify stakeholders who could provide useful information. Primary data was collected through field observation and mapping of the Mvog Betsi market. This market was chosen for special mapping due to the fact that it has an official segmentation plan that is seriously implemented. The degree of multiplicity of zones trading in similar activities within the same market and the punctuation of incompatible activities within these segments was used to determine the level of planning within the various markets of the Yaounde metropolis.

\section{Conceptual Frameworks}

This study is rooted within the context of Space/Time Geography. The daily activities of humans; eating, sleeping, traveling between home and destination, working or attending classes-all consume time as well as involve space. "... time tyrannically means the spatial choices we can make and the activity space we can command" (Fellman et al., 2005). How organised a market is affects our choices of shopping in terms of location, time spent in the activity and other extraneous factors like financial expenditure, endurance and stress. Space and time are resources. Just as we use space as a resource, allocating particular portions to particular uses, so we use time as a resource allocating particular intervals to particular uses (Nigel, 1977). As regards markets, the concept of segmentation is very significant as a medium through which space is modified over time. Human activities and interactions in space and time drive most social and economic phenomena (Harvey, 2005). Space is a system which comprises of interactions, flows and linkages. Space also has significance and a particular geographic form achieved through multiple relationships. The relationship between space and time comes from the fact that space evolves and is transformed. The idea of time is not only limited to evolution. It has value, use and most often, there is conflict and struggle over it.

Market segmentation refers to the process of dividing a mass market into meaningful, relatively similar and identifiable groups, so as to obtain an organised, efficient and desirable place for economic operators and buyers to function in it (Blythe, 2005; Baines et al., 2011). These segments comprise of like-minded individuals. That is, merchants who trade in similar products and clients with similar taste, demands and preferences. The end result of segmentation is a market where identifiable differences exist between segments (segment heterogeneity) and similarities exists between members within each segment (member homogeneity) as shown in Figure 2.

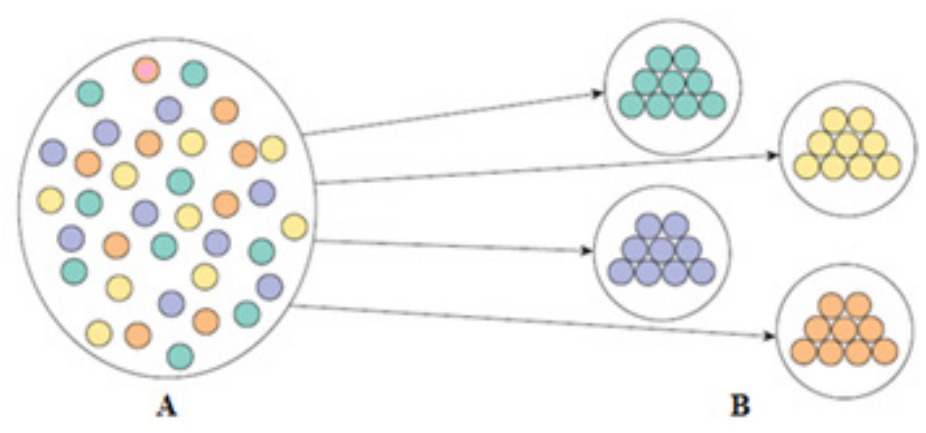

Figure 2. (A) Segment heterogeneity; (B) Segment homogeneity

Source: Baines et al., 2011.

The two main approaches to segmentation are Customer Needs-Based and Characteristic (demographic, psychographic, geography and geo-demographics) segmentation. The former entails segmenting the market based on understanding the needs of the end user while the latter is based on convenience of the trader. In Yaounde the zoning of markets into identical merchandise is a reflection of the customer orientation approach. The arrangement of objects in space determines the ease for user interaction over the market space and time. Time is a major determinant of the efficiency of a system. This study shall be limited to segment homogeneity in terms of market organisation that targets similar products in order to satisfy the end user. 


\section{Results and Analysis}

Themes considered for this analysis are presented as results on markets with a segmentation plan, markets without an official market segmentation plan and the perspective of traders on market segmentation.

\subsection{The Mvog Betsi Market Segmentation Plan}

The Mvog Betsi market (Figure 3) was organised based on the concept of compatibility. The plan is made up of three main sectors; provision stores, foodstuffs, and clothing. Space for vehicle parking and refuse has also been delimited. No activity on the plan can be a nuisance to the other. This plan is advertised on a billboard at the entrance of the market so as to direct service users. It should be noted that $50 \%$ of the market consists of un-organised zones; $12 \%$ of which does not appear on the plan but is on the actual site. The area of strict conformity consists of two zones without economic activity and one zone comprising of a bar. Maize mills are haphazardly distributed in four different locations whereas they have been assigned to one segment of the market.

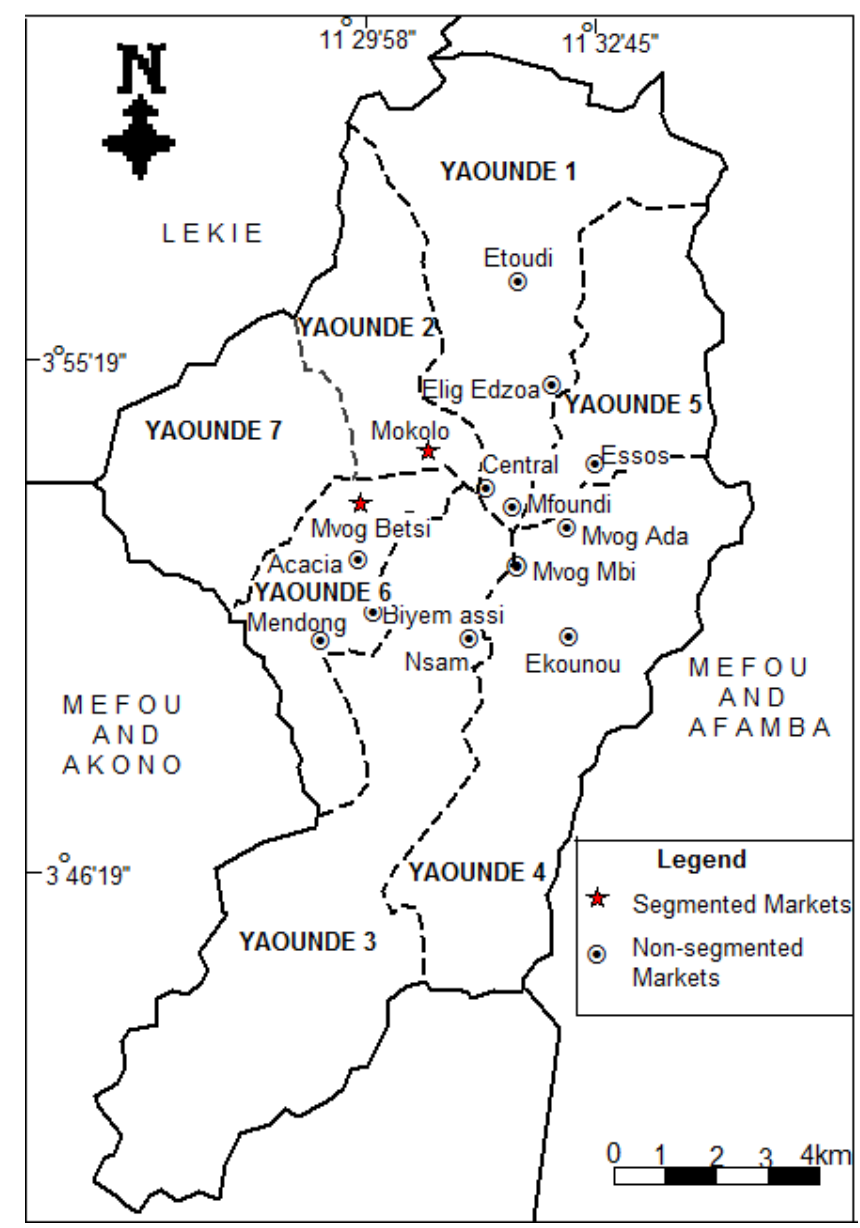

Figure 3. Markets in the Yaounde, Metropolis

Source: Fieldwork, 2012.

North of the escarpment constitutes the unattractive trade zone. Proof of this is reflected by the unoccupied stores shown in Figure 4 (Plate 1). The trade in livestock was exempted from this market but traders in fowls have invaded the paths and street as seen in Plate 2. South of the escarpment is the most attractive zone, characterised by the chaotic disposition of economic activities (Plate 3). In the same Plate (3) space allocated for the sale of perishables has been invaded by clothing. 


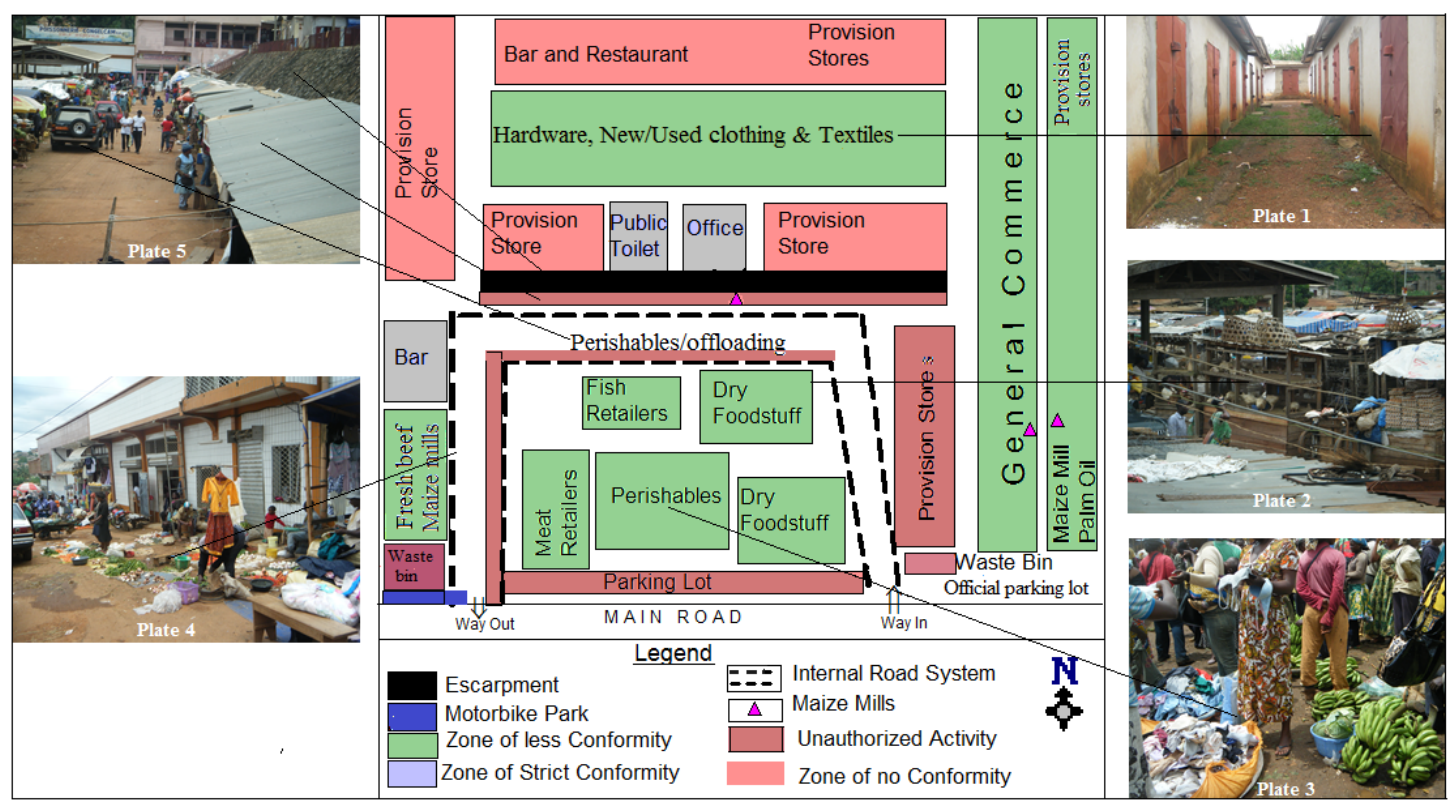

Figure 4. Segmentation and application in the Mvog Betsi market, Yaounde

Source: Fieldwork, 2012.

Plate 4 shows refrigerated stores in its authorized zone in front of which are unauthorised traders who have massively occupied the internal road system. Plate 5 shows the escarpment between the "attractive" north and the 'unattractive' south as well as zones which are not in the market plan. Traders have massively encroached on the parking space so much so that areas around the internal road system are rather used for parking.

\subsection{Mokolo Market Segmentation Plan}

Order $\mathrm{N}^{0} 159 / \mathrm{CAB} / \mathrm{DLG} / \mathrm{CUY} / 12$ by the Government Delegate of the Yaounde City Council in June 2012 authorised the segmentation of the Mokolo market into seven sectors to correspond to foodstuff, clothing, electronics/household appliances, stationery, beef/fish, petty trading and small-scale services like tailoring and shoe mending. The press release does not state whether identical commodities within a segment should be grouped. This implies that the sale of tubers and cereals in the foodstuff sector may not necessarily operate in similar segments. Consequently, there is a multiplicity of trading activity not in conformity with the text due to structural problems, indiscipline of traders, insecurity and poor enforcement.

\subsubsection{Structural Problems}

The conception of the Mokolo market as well as rehabilitation works undertaken prior to segmentation efforts did not take into consideration zoning criteria. Particular segments were not constructed to match the kind of activities to be carried out within it. As a result, it has been difficult to segment the market strictly according to identical goods and services. For instance, the foodstuff sector is associated with clothing because of the presence of shops in that sector not designed to handle perishables. Those affected by the relocation use mainly stalls and are not prepared to operate in enclosed structures (shops). Traders of clothing who operate in shops have maintained their position thereby leading to the absence of homogeneity in land use. In the fruit segment found in the foodstuff sector, all the traders (100\%) complain about the ill-adapted nature of the sheds to handle their delicate goods (Table 1). In their opinion, fruits are supposed to be sold in an open and airy environment so as to avoid moisture, mould and eventual damage. As a result, traders have vacated the premises which have been invaded by tailoring activity.

\subsubsection{Indiscipline and Insecurity}

About $10 \%$ of traders maintained that their line of activity does not conform with what has to prevail within the segment where they used to operate prior to the segmentation. These are mainly women who trade in perishables in the fish and meat sector. These women are not prepared to evacuate from their sales space as they prefer to switch to the activity of the zone in which they are found for fear of moving to a relatively disadvantaged position compared to their present location. Others claim that there is no space to accommodate them in the area in which similar commodities are sold. $80 \%$ of them state that they need time to raise capital to switch to the 
trade that conforms to the zone in which they are found.

The chaotic distribution experienced in this market is also as a result of inadequate security. Each zone has a security team. However, the irregularity in remunerating the team has weakened their enforcement capacity and has encouraged the violation of the segmentation order. The non-respect of zones is also a serious problem in this market. Some $10 \%$ of non-conformist traders handling perishables prefer to use their stalls as a parking store, while operating as peddlers with small quantities around the market. This has also been encouraged by the presence of street vendors who are believed to be in closer contact with buyers more especially as they operate along the streets and market entrance than those who are in fixed locations.

Table 1. Reasons for non-respect by traders of allocated space

\begin{tabular}{lccc}
\hline \multirow{2}{*}{ Reason } & \multicolumn{3}{c}{ Opinion (\%) } \\
& Yes & No & Don't know \\
\hline Poor location & 80 & 8 & 2 \\
Ill-adapted sheds & 100 & 0 & 0 \\
Prefer to operate in the open & 74 & 20 & 6 \\
No space in zone allocated & 55 & 30 & 15 \\
\hline
\end{tabular}

Source: Fieldwork, 2012.

\subsubsection{Congestion}

The efficient zoning of the Mokolo market has been hampered by its overcrowded nature as attested by $55 \%$ of the sampled population against $30 \%$ as illustrated in Table 1 . The site constructed for petty traders can accommodate only 300 traders whereas those in need are over 2000. Furthermore, only two sheds have been attributed to those in the merger job sector. This is largely insufficient and has led to activities that do not conform in other sectors of the market in order to accommodate the plethora of traders in search of space.

\section{Implications of Non-Organised Markets}

$80 \%$ of the markets in Yaounde (Central market, Mfoundi, EligEdzoa, Etoudi, Essos, Ekounou, Mendong, Acacia, Nsam, Etoudi and Mvog Mbi) are not officially segmented. In spite of this, markets that have been officially segmented still leave much to be desired as revealed by the Mokolo market for example. This notwithstanding, this study reveals that there are a multitude of socioeconomic implications arising as a result of markets not being officially segmented.

\subsection{Layout of Goods and Services}

There is a certain level of compatibility which has been established amidst the chaotic disposition of goods in markets with no zoning regulation. Smoked fish, fresh meat and fish are often sold besides customers who trade in vegetables, spices and tomatoes. The anarchy in the location of economic activities kills the idea of effective competition within the business environment. This often leads to great disparities in prices of similar goods in quality and quantity. Furthermore, it makes shopping tedious because customers spend more time and energy to be able to spot out where they can find similar goods of better quality, quantity or at affordable prices. Table 2 shows an association of incompatible activities observed in Yaounde markets and their likely outcomes.

\subsection{Street Vending}

In Yaounde markets, trading along pedestrian paths is thought to be very lucrative due to a faster turnover. Vending along pedestrian walks is more conspicuous especially as from $4 \mathrm{pm}$ (towards the close of the market day). In the Mvog Mbi market, traders have virtually abandoned their market space to concentrate along the streets. According to the head of the fresh meat sector, the sheds allocated to them has the capacity to accommodate fifty-four traders. However, only $7.4 \%$ of the traders have effectively occupied the space. As such, meat vendors have deserted their space in favour of street trading. They expose meat in trays, wheel barrows and on stalls by the road side.

The majority of traders who sell meat along the road do so on movable wooden structures (stalls). Similarly, in the Mvog Ada market, livestock vendors have installed almost permanently along the road where they sell fowls in baskets, while those in the Mfoundi market are itinerants. The overall effect of this is that this chaotic 
disposition of goods along pathways and streets has led to frequent traffic jams. For example from the Coron to Mvog Mbi junction which is a distance of $1 \mathrm{~km}$, the average time a vehicle takes to go through is between 15 to 30 minutes instead of 1 minutes when the market is not in operation.

Table 2. Incompatible activities and likely effects in Yaounde markets

\begin{tabular}{|c|c|c|}
\hline Market & Incompatible Activities & Likely Effects \\
\hline Mvog Betsi & Hair dressing next to food catering. & Food poisoning. \\
\hline \multirow[t]{2}{*}{ Mvog Mbi } & Cooking and serving food besides a toilet. & Food Poisoning and foul smell. \\
\hline & $\begin{array}{l}\text { Cooking with wood and sawdust close to } \\
\text { vendors. }\end{array}$ & $\begin{array}{l}\text { Smoke discomfort, depreciation of clothes } \\
\text { because of the accumulation of } \mathrm{CH}_{4} \text { and } \mathrm{NH}_{3}\end{array}$ \\
\hline Mfoundi & Perishables besides garbage bins. & Food poisoning. \\
\hline Ekounou & Maize mills in proximity to clothing. & $\begin{array}{l}\text { Susceptibility to respiratory tract infections } \\
\text { (cough and catarrh), depreciation of clothing. }\end{array}$ \\
\hline \multirow[t]{2}{*}{ Essos } & Perishables besides clothing. & $\begin{array}{l}\text { Depreciation in value of clothing due to constant } \\
\text { sprinkling of water on perishables which affect } \\
\text { clothing. }\end{array}$ \\
\hline & Oil sales in proximity to clothing. & $\begin{array}{l}\text { Depreciation of clothing and collision between } \\
\text { traders }\end{array}$ \\
\hline Mokolo & $\begin{array}{l}\text { Road side vending (food and general } \\
\text { merchandise) }\end{array}$ & $\begin{array}{l}\text { Vehicular and pedestrian congestion, pollution } \\
\text { and food poisoning. }\end{array}$ \\
\hline
\end{tabular}

NB. Information on the table is based on markets with and without a segmentation plan.

Source: Fieldwork; Health and Sanitation Department, Yaounde City Council, 2012.

\subsection{Trading Above Ground Level}

The municipal authorities introduced the notion of organized markets not only in terms of segmentation in activities but also in the sale of goods and services within storey blocks since the past 30 years. This at the time was a new phenomenon in the African market system and since then, very little success has been achieved in attracting both traders and buyers to shops above ground level. The low occupancy of shops in the upper floors can also be blamed on the absence of segmentation. The more storeys you climb, the lower the level of stall occupancy. This is the case in the Central market which has five levels. The fourth and fifth storeys are somewhat deserted as shown in Figure 5. It was noticed that 130 stalls in the Central market and $56 \%$ of those in Mokolo are not functional in spite of the fact that traders have been assigned to them. The reasons advanced by the traders are due to low population potential and from field observation, buyers can easily obtain those goods at ground level due to proximity and less time spent.

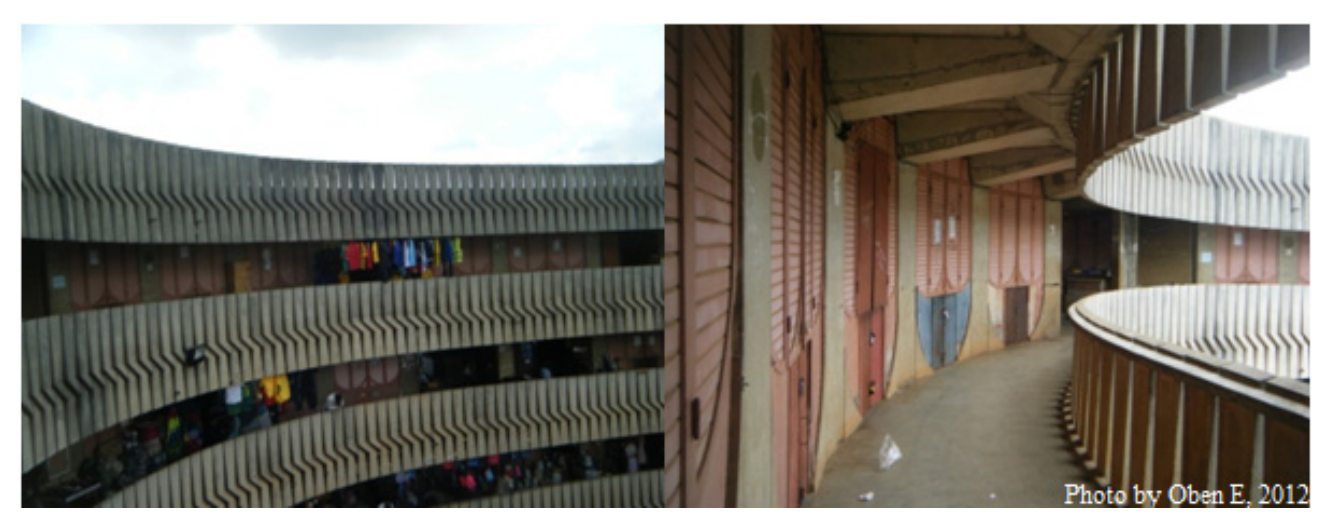

Figure 5. Low occupancy of upper level shops in the Central market, Yaounde

Photo has been taken on a market day with absence of traders and buyers on the 3rd floor. 


\subsection{Security Concerns}

The chaotic disposition of economic activities has led to the emergence of a group of boys locally called appacheur (Market Guides) chiefly in the Central and Mokolo markets of Yaounde. Majority of them are located at the entrance of the market, seeking to know the needs of customers so as to guide them. In this process, customers are often harassed and robbed. A buyer's ignorance of the market situation, can lead him/her to an isolated area to be robbed. Cases of theft occur daily and fire outbreaks recurrent and difficult to be dealt with due to the anarchy in the use of trading spaces in the various unorganised markets.

\subsection{Collision and Confrontation}

$71 \%$ of traders are in favour of official segmentation. This notwithstanding, cases of collision often occurs between market authorities of the Yaounde City Council, police officers on one hand and traders on the other. According to the Commissioner of Police at the Mokolo Police District, there were four confrontations between authorities and traders, between January and October of 2012. The conflict on the $16^{\text {th }}$ of June, 2012 witnessed the death of a trader and the arrest of several others. According to the former Registrar of the Mfoundi market who is presently the Registrar of the Central market, the presence of an organised criminal cartel of traders challenge market reforms. This is because their members maximise profits in the chaotic setup of the market.

\section{Discussions}

As a result of the disorganised nature of markets in Yaounde, it is difficult to determine and manage retail space and as a result, markets are often congested. According to Balla (2008) the Mvog Mbi market has expanded by 300 percent its initial size. This has concomitant effects on the contiguous urban space that is supposed to accommodate other urban land uses and thus create an urban planning problem. Organised markets have brought about a number of changes with respect to infrastructural development and the layout of goods and services when compared to non-organised markets. In the Mokolo market, structures have been provided that conforms to goods sold. For example, stalls used for trade in groundnuts are specially designed (having a width of $1 \mathrm{~m}^{2}$ and a height of $65 \mathrm{~cm}$ ) which prevents groundnuts from spilling to other areas. In as much as the shops are designed to accommodate specific kinds of foodstuffs or services, there are also considerations for the maximisation of space for each trader in view of achieving an overall market space for circulation (pedestrians/movable objects) and parking (goods/vehicles) in the market. This aspect is a very important consideration alluded to by Fellman (2005) because in the final analysis, distance between the various shops and parking lots is reduced, thereby enabling both users and suppliers to maximise space and time within the urban landscape.

The absence of market segmentation has ushered into the marketing sphere a set of intermediaries between the vendor and buyer acting as guides with the understanding that they master the location of various commodities and services. In essence, one of the rational for segmenting the markets is to render trading and buying easy, fraught of insecurity both for the indigenous population and newly arrived into the city. In Yaounde markets, formal retail establishments use informal workers in order to expand their market. This situation was equally observed by the International Labour Organisation (ILO) (2002). There are several disadvantages linked to this kind of system for the following reasons;

- Buying operation in a market place is personal. The presence of such intermediaries invalidates the privacy of the buyer and exposes the latter to acts of aggression which is a characteristic feature of such markets.

- Intermediaries cause price hikes since they act as informants to the buyer. They enhance the sale of goods of traders they favoured and so expect some remuneration at the end of the day which from field studies can range between 500 to 1000 FCFA ( 1 to 2 USD) or less than depending on the quality of the good purchased. Also at the end of the purchase, the buyer is expected to remunerate the intermediary.

In Figure 2, only two markets in Yaounde are segmented and located in the western part of the city while the majority are found in the northeast. This makes the segmented ones more attractive to buyers, but at the same time, they experience planning problems because they attract the bulk of buyers, from all parts of the city, thereby creating problems of circulation in the market, artificial price hikes and ills that are identified with the un-organised markets. Supply may be limited, congestion leads to insecurity, fire outbreaks (Adekunle, 2012), necessitating more traffic police and other resources to address such problems.

The presence of street vendors has made trade in the market to become relatively unprofitable. This occurrence was also noticed by UN-HABITAT (2010), at the end of the civil war in the Hargeisa Central market in Somalia. This category of vendors only thrive where there is chaos within the market environment as noticed with most of the un-organised markets. Provision of basic infrastructures within market premises to cater for the needs of both 
suppliers and users is the first major step to ensuring better management of space and time.

Congestion has been noticed in all the markets either resulting from lack of segmentation or due to irrational use of space especially by street sellers and peddlers. This demographic problem can be explained by the fact that African cities have not developed on industrialisation, thus, they lack the productive base to provide alternative opportunities to the growing population as indicated by Carter (1982), UN-HABITAT (2010) in various studies. According to Abu-Lughod et al. (1974) in Fombe and Balgah (2010) they are "victims of urbanisation without industrialisation".

\section{Conclusion}

The absence of a priori segmentation is the main cause of disorder in Yaounde city markets. The challenges of segmentation have a structural and socioeconomic implication for the buyers, sellers, the entire urban population and city planning proponents. Though there is still much to be desired from the segmented markets in the overall development of the Yaounde city, the Mokolo and Mvog Betsi markets have modified the market space and facilitated shopping by its users. Market segmentation option is worthy of praise given the city's cosmopolitan nature and the numerous socio-economic problems and chaos that characterises the non-organised markets. Market improvement programs can generate positive socioeconomic benefits by virtue of the fact that it would improve the efficiency of market operations, health protection and improvements on the amenities and aesthetics of markets.

The planning of the urban economic space within the context of sustainable development leaves much to be desired if the city dwellers do not participate in the overall development of their environment. Urban sustainability is a long journey and each sector within the urban realm has to contribute in the urban development process if the Millennium Development Goals have to make meaning in the capital of Cameroon in particular and Third World urban landscapes in general.

\section{Recommendations}

There is need to decongest the markets so as to foster the segmentation drive. This can partly be achieved through creating other market poles especially in the southern part of the city. This should be accompanied by segmentation a priori before effective occupation. Market segmentation initiatives should be integrated in the development plans of markets so as to achieve an organised, efficient and desirable place for economic operators and buyers to function. Education of traders through the media is primordial and a prerequisite for any effective management of market space as they are often the first people to make use of such urban land-use for economic purposes.

Market management by the municipality should be reinforced so as to eliminate old and bad habits such as street sales that has characterised almost all the urban markets. The presence of security guards cannot be underestimated as they play a preponderant role in deterring obnoxious attitudes of traders. There is need for the re-segmentation of the Mvog Betsi market and wholesale activities integrated in this market. This is in a bid to redress the anarchy and improve on the marketability of the site.

This study suggests a gradual implementation of similar segmentation drives in the other markets (and those in view of development as in the south of Yaounde) for an effective spatial planning result. Frequent fire disasters could be avoided if markets are well segmented and adequate infrastructures like water, electricity open spaces, among others are provided which is not often the case in the urban markets due to limitation of space.

The concept of segmentation in view to ensure the efficient operation of traders and buyers in 'traditional' markets should at this stage of city growth be limited to ground level operations since the underutilisation of the Yaounde central market constructed to host buyers and traders in buildings with multiple floors epitomises some degree of failure. Urbanism as a way of city living is connected to cultural values and the stage of urbanization of a city. The rapidly expanding population of Yaounde is more the result of rural exodus and internal dynamism than immigration for alien cultures to find a playground that can produce the kind of markets that operate in Western cities.

\section{References}

Adekunle, F. B. (2012). Management of traditional markets in Ibadan, Nigeria: A focus on Oja'ba and Oje markets. $\quad$ Retrieved August 29, 2012, from http://www.regionalstudies.org/uploads/balogun_femi_adekunle.pdf

Baines, P., Fill, C., \& Page, K. (2011). Marketing (2nd ed.). Oxford University Press, Oxford.

Balla, O. O. B. (2008). L'Extension spatiale du Marché Mvog-Mbi, ses effets socioéconomiques et son rôle dans 
la structuration du cadre urbain environnant (Unpublished thesis). Département de Géographie, FLSH, Université de Yaoundé I.

Blythe, J. (2005). Essential of marketing. (3rd ed.). Pearson Education Ltd, Edinburg.

Carter, H. (1982). The study of urban geography. London: Arnold.

Fellmann, J. D., Getis, A., \& Getis, J. (2005). Human Geography; Landscapes of Human Activities (8th ed.). New York: Mc Graw Hill.

Fombe, L. F., \& Balgah, S. N. (2010). The Urbanisation process in Cameroon: Patterns, Implications and Prospects. New York: Nova Science Publisher, Inc.

Fresno, J. M., \& Koops, R. (2000). Market trading in Europe: methodological guide for the analysis and enhancement of markets in public areas. Hague: Union Européenne du Commerce Ambulant (UECA), pp 13, 24-30.

International Labor Organization (ILO). (2002). Decent work and the informal economy. International Labour Conference, $90^{\text {th }}$ Session, Report VI, International Labour Office, Geneva.

Miller, H. J. (2005). Necessary space-time conditions for human interaction. Environment and Planning B: Planning and Design, 32(3), 381-401. http://dx.doi.org/10.1068/b31154

Plan Directeur D'Urbanisme. (2008). Yaounde 2020: Project de ville de Yaounde 2010-2015. Ministry of Housing and Urban Development and Yaounde City Council, Yaounde.

Simone, A. M. (1999). Thinking about African urban management in an era of globalisation. African Sociological Review/Revue Africaine de Sociologie, 3(2), 69-98. http://dx.doi.org/10.4314/asr.v3i2.23166

Thomas, J. W. (2007). Market segmentation, Arlington. Decision analyst.

Thrift, N. (1977, January). An introduction to time-geography. Geo Abstracts, University of East Anglia.

Tracy-White, J. D. (1995). Retail market planning guide. FAO Agricultural Service Bulletin, Fiat Panis, Rome.

UN-HABITAT. (2010). Planning Sustainable Cities. UN-HABITAT practices and perspectives, Nairobi, Kenya.

Uzuegbunam, F. O. (2012). Sustainable Development for Traditional Market-Places in South-Eastern Nigeria: A Case Study of Nkwo-Ozuluogu Market in Oraifite, Anambra State, Nigeria. Journal of Environmental Management and Safety, 3(1), 139-158.

Yaounde City Council. (2012). Press Release N ${ }^{0}$ 159/CAB/DLG/CUY/12 of 21 June, 2012 by the Government Delegate, Yaounde.

\section{Copyrights}

Copyright for this article is retained by the author(s), with first publication rights granted to the journal.

This is an open-access article distributed under the terms and conditions of the Creative Commons Attribution license (http://creativecommons.org/licenses/by/3.0/). 